\title{
The interplay of intrinsic excitability and network topology in spatiotemporal pattern generation in neural networks
}

James P Roach ${ }^{1 *}$, Leonard M Sander ${ }^{2}$, Michal R Zochowski

From The Twenty Third Annual Computational Neuroscience Meeting: CNS*2014

Québec City, Canada. 26-31 July 2014

It is clear that spatiotemporal patterning in brain networks is a complex outcome of network physical connectivity and dynamical properties of interacting neurons, however characterization of this interaction remains elusive. These dynamical properties of the cells are affected/controlled by various neuromodulators secreted by the brain at various cognitive cycles or as a part of the response to the incoming stimuli. During sleep the brain cycles though distinct spatiotemporal patterns of neural activity. Acetylcholine $(\mathrm{ACh})$ is a major regulatory factor of sleep states and plays an important role in the transition from slow wave sleep to waking or rapid eye movement sleep. Slow wave sleep is a slow oscillation in firing rate that travels through the cortical network and occurs when ACh levels are low [1]. At the cellular level, ACh causes changes in neural excitability by shifting the neural phase response curve (PRC)

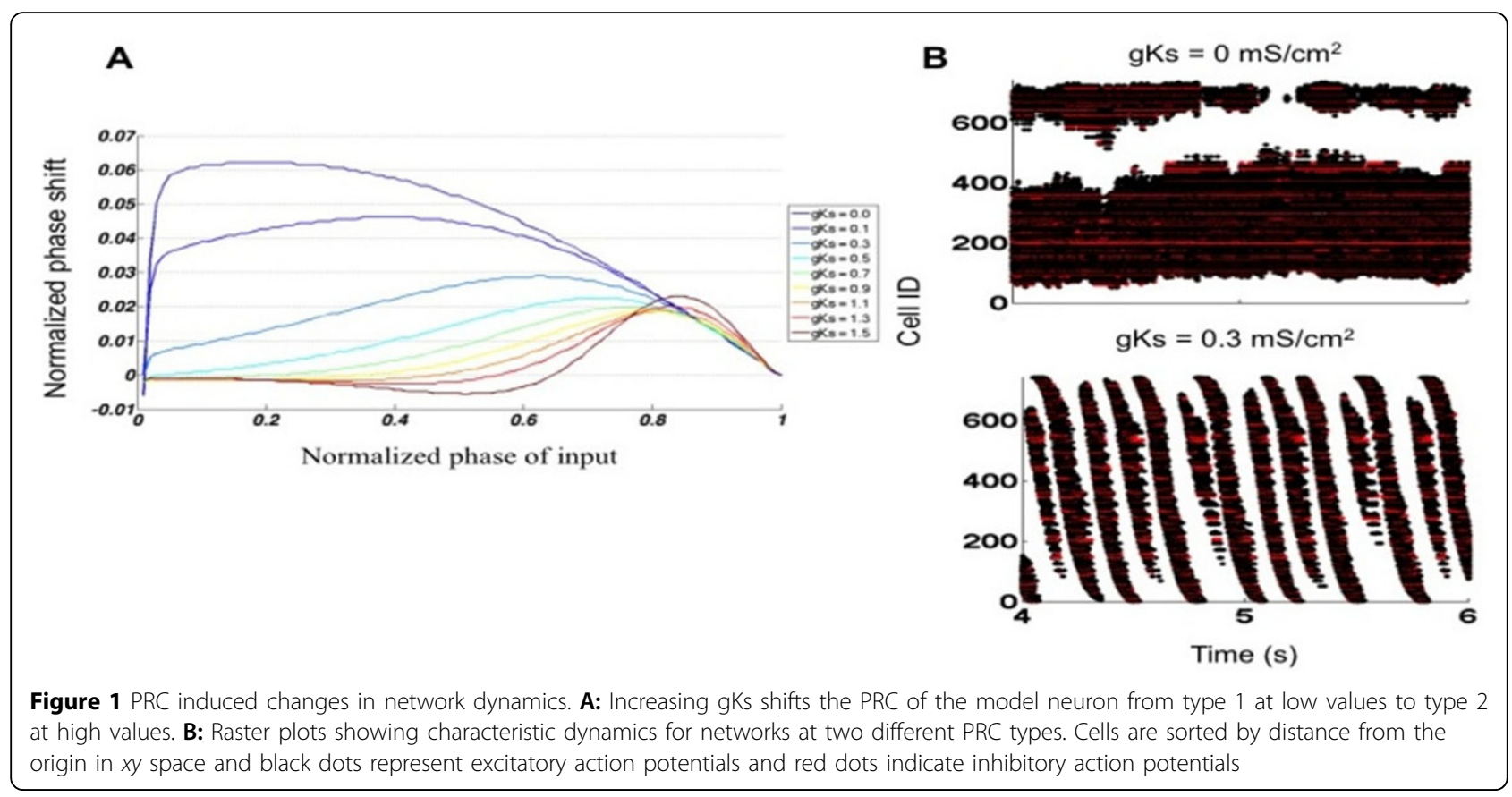

\footnotetext{
* Correspondence: roachjp@umich.edu

'Neuroscience Graduate Program, University of Michigan, Ann Arbor, Ml 48109, USA

Full list of author information is available at the end of the article
} 
from type 2 to type 1 (Figure 1A)[2]. Previous modeling studies show that the shift of the PRC leads to a change from synchronous (type 2 PRC) to asynchronous (type 1 PRC), network dynamics while during low ACh levels networks display a high level of synchrony and network wide bursts [3]. As of yet the effects of intermediate cholinergic modulation have not been investigated. In this study, we use a Hodgkin-Huxley type model neuron which allows us to simulate different ACh levels and control a continuous transition from a type 1 to type 2 PRC [4]. We show that the PRC type of neurons drives different spatial patterns of activity within networks, with activity being highly localized for type 1 PRC neurons (Figure 1B) then quickly transitioning to wave dynamics as neurons are shifted to a type 2 PRC (Figure 1B). In networks composed of type 1 neurons, the region where activity is localized is defined by heterogeneities in network structure, with as little as a $1 \%$ increase in synaptic strength being sufficient to define the location of high activity. Additionally, the highly active zone is the origin of traveling waves in type 2 networks. When in the wave regime, decreasing cholinergic modulation of the PRC increases the speed that waves travel across the network. In summary, the precise character of frequency dynamics is governed by the interplay between network structure and the intrinsic excitability of component neurons. Expanding upon our results, we argue (1) that the intrinsic excitability of neurons shapes how activity spreads though a network and (2) that the focal point of traveling waves during slow wave sleep is a region selected for by synaptic potentiation.

\section{Acknowledgements}

This material is based upon work supported by the NSF GRFP under Grant No. DGE 1256260 (JPR), NSF CMMI 1029388 (MRZ), and NSF PoLS 1058034 (MRZ \& LMS).

\section{Authors' details}

${ }^{1}$ Neuroscience Graduate Program, University of Michigan, Ann Arbor, MI 48109, USA. ${ }^{2}$ Department of Physics, University of Michigan, Ann Arbor, Ml 48109, USA.

Published: 21 July 2014

\section{References}

1. Massimini M: The Sleep Slow Oscillation as a Traveling Wave. Journal of Neuroscience 2004, 24:6862-6870.

2. Stiefel KM, Gutkin BS, Sejnowski TJ: Cholinergic Neuromodulation Changes Phase Response Curve Shape and Type in Cortical Pyramidal Neurons. PLOS ONE 2008, 3:e3947.

3. Fink CG, Booth V, Zochowski M: Cellularly-Driven Differences in Network Synchronization Propensity Are Differentially Modulated by Firing Frequency. PLoS Comput Biol 2011, 7:e1002062.

4. Stiefel KM, Gutkin BS, Sejnowski TJ: The effects of cholinergic neuromodulation on neuronal phase-response curves of modeled cortical neurons. J Comput Neurosci 2008, 26:289-301.

doi:10.1186/1471-2202-15-S1-016

Cite this article as: Roach et al:: The interplay of intrinsic excitability and network topology in spatiotemporal pattern generation in neural networks. BMC Neuroscience 2014 15(Suppl 1):016.

\section{Submit your next manuscript to BioMed Central and take full advantage of:}

- Convenient online submission

- Thorough peer review

- No space constraints or color figure charges

- Immediate publication on acceptance

- Inclusion in PubMed, CAS, Scopus and Google Scholar

- Research which is freely available for redistribution 